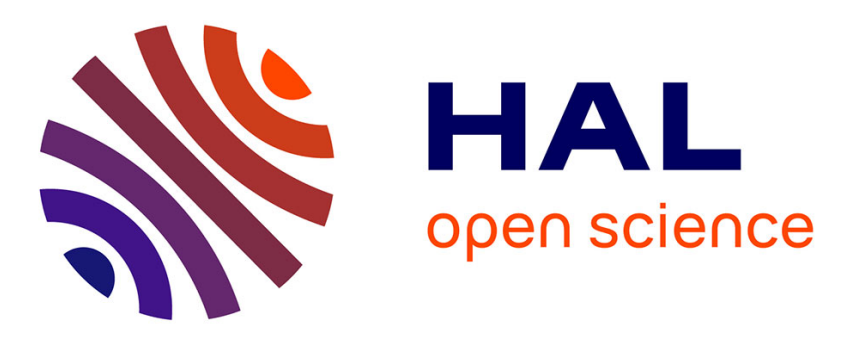

\title{
In vitro Analysis of Localized Aneurysm Rupture
}

Aaron Romo, Pierre Badel, Ambroise Duprey, Jean-Pierre Favre, Stéphane

Avril

\section{To cite this version:}

Aaron Romo, Pierre Badel, Ambroise Duprey, Jean-Pierre Favre, Stéphane Avril. In vitro Analysis of Localized Aneurysm Rupture. Journal of Biomechanics, 2014, 47 (3), pp.607-616. hal-01025664

\section{HAL Id: hal-01025664 \\ https://hal.science/hal-01025664}

Submitted on 18 Jul 2014

HAL is a multi-disciplinary open access archive for the deposit and dissemination of scientific research documents, whether they are published or not. The documents may come from teaching and research institutions in France or abroad, or from public or private research centers.
L'archive ouverte pluridisciplinaire $\mathbf{H A L}$, est destinée au dépôt et à la diffusion de documents scientifiques de niveau recherche, publiés ou non, émanant des établissements d'enseignement et de recherche français ou étrangers, des laboratoires publics ou privés. 
Corresponding author:

Aaron Romo

Center for Health Engineering

Ecole Nationale Supérieure des Mines

158 cours Fauriel

42023 SAINT-ETIENNE CEDEX 2 France

Phone: +33477429329

Fax: +33477499755

Email: romo@emse.fr

\section{KEYWORDS}

Aneurysm, human aorta, inflation test, rupture, ultimate stress.

\section{In vitro Analysis of Localized Aneurysm Rupture}

${ }^{1}$ Ecole Nationale Supérieure des Mines de Saint-Etienne, CIS-EMSE, CNRS:UMR5146, LCG, F-42023 Saint Etienne, France ${ }^{2}$ Hôpital Nord, Cardiovascular Surgery Service, CHU de Saint Etienne, F-42055 Saint-Etienne cedex 2, France. 
In this study, bulge inflation tests were used to characterize the failure response of 15 layers of human ascending thoracic aortic aneurysms (ATAA). Full field displacement data were collected during each of the mechanical tests using a digital image stereo-correlation (DIS-C) system. Using the collected displacement data, the local stress fields at burst were derived and the thickness evolution was estimated during the inflation tests. It was shown that rupture of the ATAA does not systematically occur at the location of maximum stress, but in a weakened zone of the tissue where the measured fields show strain localization and localized thinning of the wall. Our results are the first to show the existence of weakened zones in the aneurysmal tissue when rupture is imminent. An understanding these local rupture mechanics is necessary to improve clinical assessments of aneurysm rupture risk. Further studies must be performed to determine if these weakened zones can be detected in vivo using non-invasive techniques.

44 


\section{INTRODUCTION}

Each year thoracic aneurysms are diagnosed in approximately 15,000 people in the United States and more than 30,000 people in Europe (Clouse 1998). Of this number $50-60 \%$ are ascending thoracic aortic aneurysms (ATAA) (Isselbacher 2005). However the rupture of the ATAA remains an almost unexplored topic. ATAAs are caused by the remodeling of the arterial wall and they rupture when the stress applied to the aortic wall locally exceeds its capacity to sustain stress (Vorp et al., 2003).

In an attempt to understand the mechanical behavior of the aortic tissue; different authors have performed mechanical tests. Uniaxial tensile tests were performed by (Mohan and Melvin, 1982) on healthy descending aortic specimens; they concluded that the most reasonable failure theory for aortic tissue was the maximum tensile strain theory. (He and Roach, 1994) also performed uniaxial tensile tests and showed that aneurysms were less distensible and stiffer than healthy tissues. Using uniaxial tensile tests to compare healthy tissues with ATAA specimens (Garcia-Herrera et al., 2011) concluded that the age, beyond the age of 35 , was the cause of significant decrease of rupture load and elongation at failure. They found no significant differences between the mechanical strength of aneurysms and healthy tissues. In contrast, (Vorp et al., 2003) found a significant decrease in the tensile strength of the ATAA specimens and concluded that its formation was associated with the stiffening and weakening of the aortic wall. Providing data on the mechanical behavior in the physiological range, (Duprey et al., 2010) found that the aortic wall was significantly anisotropic with the circumferentially oriented samples being stiffer than the axial ones.

The biaxial mechanical behavior of the aortic tissue has been investigated with bulge inflation tests. Dynamic and quasi-static bulge inflation tests (Mohan and Melvin, 1983) were performed on healthy descending aortas. The failure of the aortic tissue always took place with a tear in the circumferential direction. Similarly, (Marra et al., 2006) performed inflation tests using porcine healthy aortic tissues, 
showing that the rupture occurs with a crack oriented in the circumferential direction of the artery. More recently (Kim et al., 2012) performed inflation tests using ATAA specimens. Material parameters were identified using the virtual fields method (Grédiac et al., 2006; Avril et al., 2010) and the average Cauchy stress values at which the rupture occurred were derived for all the specimens.

None of the studies mentioned above analyzed locally the rupture of the tissue from its first initiation. Moreover, all these studies derived an average stress estimation across the specimens and none were able to show if the rupture initiates at the location of maximum stress or if the rupture was triggered by the existence of weakened parts within the tissue. Our objective was to address this issue by carrying out full-field measurements in human ATAA specimens tested in a bulge inflation test up to failure. In order to determine the cause and location of the rupture, thickness evolution estimations and local stress distributions were calculated during the inflation of the specimens. 


\section{METHODS}

\section{Sample Preparation and Experimental Protocol}

ATAA specimens were obtained from donor patients who underwent surgical replacement of their ATAA with a synthetic graft. The collection of the aortic tissues was done in accordance with the guidelines of the Institutional Review Board of the University Hospital Center of Saint-Etienne. Specimens were kept at $4{ }^{\circ} \mathrm{C}$ in $0.9 \%$ physiological saline solution and testing was completed within 24 hours of tissue harvest (Adham et al. 1996). Table 1 lists the demographic information for the collected ATAA specimens.

Each ATAA (Fig. 1-a) was cut into square specimen approximately $45 \times 45 \mathrm{~mm}$. Each specimen was then separated into two layers: intima-media and adventitia (Fig. 1-b). The average thickness of each layer was measured using digital calipers; the layer of interest was put between two plastic plates and the thickness of the layer and the plates was measured. Then the thickness of the two plates was subtracted from the measured value. The ATAA layer was clamped in the inflation device so that the luminal side of the tissue faced outward and the circumferential direction of the artery coincided with the horizontal axis of the clamp (Fig. 1-c). Finally a speckle pattern was applied to each sample using black spray paint (Fig. 1-c). Note that the luminal side of each layer was chosen to face outward since the adventitial surface was highly irregular making difficult for the speckle pattern to adhere to the surface.

A hermetically sealed cavity was formed between the clamped ATAA layer and the inflation device. During the inflation test, water was injected at a constant rate by pushing a piston pump at 15 $\mathrm{mm} / \mathrm{min}$ until the tissue ruptured. Simultaneously, the pressure was measured with a digital manometer (WIKA ${ }^{\oplus}$, pressure gauge DG-10). Images were recorded using a commercial DIS-C system $\left(\mathrm{GOM}^{\circledR}\right.$, ARAMIS $5 \mathrm{M} \mathrm{LT}$ ) at every $3 \mathrm{kPa}$, until the sample ruptured (Fig. 2). The DIS-C system was 


$$
\boldsymbol{g}^{\alpha}=\frac{\partial \xi^{\alpha}}{\partial \boldsymbol{x}} \quad \boldsymbol{G}^{\alpha}=\frac{\partial \xi^{\alpha}}{\partial \boldsymbol{X}}
$$
their central area (without touching the boundaries of the inflation device) were used.

\section{Data Analysis} displacement. respectively, are found using the following relationships:

$$
\boldsymbol{g}_{\alpha}=\frac{\partial \boldsymbol{x}}{\partial \xi^{\alpha}} \quad \boldsymbol{G}_{\alpha}=\frac{\partial \boldsymbol{X}}{\partial \xi^{\alpha}}
$$

The local contravariant basis vectors $g^{\alpha}$ and $G^{\alpha}$ are then defined as:

composed of two 8-bit CCD cameras equipped with $50 \mathrm{~mm}$ lenses (resolution: 1624 x 1236 px). In this study, 15 ATAA layers were successfully tested until rupture. Only the specimens that ruptured in

Once the experimental procedure was completed, image processing was performed using Aramis ${ }^{\circledR}$ software. In each of the acquired images (Fig. 2), the area of interest (AOI), which was a circle measuring $30 \mathrm{~mm}$ diameter, was identified. A facet size of $21 \mathrm{px}$ and a facet step of $5 \mathrm{px}$ were chosen based on the speckle pattern dot size, distribution, and contrast. The selected facet size and step yielded a resolution of $0.54 \mu \mathrm{m}$ for in-plane displacements and $1.5 \mu \mathrm{m}$ for the out-of-plane

To capture the kinematics of the membrane (Naghdi 1972; Green and Adkins 1970; Lu et al., 2008) we define the position vectors for a material point $P$ in the initial and deformed configurations as $\boldsymbol{X}(P)$ and $\boldsymbol{x}(P)$, respectively (Fig. 4). The surface is parameterized using a pair of surface coordinates $\xi^{\alpha}(P)=\boldsymbol{X}(P) \cdot \boldsymbol{E}_{\alpha}$ where $\boldsymbol{E}_{\alpha}$ are the basis vectors of the global coordinate system GCS (Fig. 3) and $\alpha=1,2$. The local covariant basis vectors $\boldsymbol{g}_{\alpha}$ and $\boldsymbol{G}_{\alpha}$ for the deformed and initial configurations, 
The two-dimensional deformation gradient, $\boldsymbol{F}$, is calculated from the current and initial basis vectors:

$$
\boldsymbol{F}=\boldsymbol{g}_{\alpha} \otimes \boldsymbol{G}^{\alpha}
$$

Then, at each material point, the two- dimensional Green-Lagrange strain, $\boldsymbol{E}$, is determined:

$$
\boldsymbol{E}=\frac{1}{2}\left(\boldsymbol{F}^{T} \boldsymbol{F}-\boldsymbol{I}\right)
$$

To define the three-dimensional deformation, we set $\lambda_{3}=h / h_{0}$, where $h$ and $h_{0}$ are the thicknesses in the deformed and undeformed configurations, respectively, and required the transverse shear strains to vanish. It follows that the three dimensional deformation gradient and Green-Lagrange strain tensor are given by:

$$
\boldsymbol{F}=\boldsymbol{g}_{\alpha} \otimes \boldsymbol{G}^{\alpha}+\lambda_{3} \boldsymbol{n} \otimes \boldsymbol{N} \quad \boldsymbol{E}=\frac{1}{2}\left(\boldsymbol{g}_{\alpha \beta} \boldsymbol{G}^{\alpha} \otimes \boldsymbol{G}^{\beta}+\lambda_{3}{ }^{2} \boldsymbol{N} \otimes \boldsymbol{N}-\boldsymbol{I}\right)
$$

where $\boldsymbol{n}$ and $\boldsymbol{N}$ are outward unit normals to the surface in the current and initial configurations, respectively.

\section{Determination of the Local Stress Fields}

The aneurysm wall is modeled as a nonlinear elastic membrane. A unique feature of modeling the aneurysm wall as a nonlinear elastic membrane is that the tension in the vessel wall can be determined without the use of a constitutive model to describe the elastic properties of the wall (Lu et al., 2008). The local equilibrium equations for the elastostatic problem may be written as (Lu et al., 2008; Zhao 2009): 


$$
\frac{1}{\sqrt{g}}\left(\sqrt{g} h \sigma^{\alpha \beta} \boldsymbol{g}_{\alpha}\right)_{, \beta}+p \boldsymbol{n}=\mathbf{0}
$$

where $g=\operatorname{det}\left(\boldsymbol{g}_{\alpha} \cdot \boldsymbol{g}_{\beta}\right)$ is the determinant of the metric tensor, $h$ is the current thickness, $p$ is the internal pressure applied for the inflation and $\sigma^{\alpha \beta}$ are the unknown components of the Cauchy stress tensor $\boldsymbol{\sigma}$ in the local covariant basis. Note that Eq. (6) is in tensorial form and the Einstein summation convention is used. Then, we approximate the spatial variations of all the quantities of Eq. (6) using linear shape functions of the surface coordinates which take on a null value at all nodes of the mesh except at node $k$ where it is 1 . The shape functions are defined on a triangular finite element mesh having $N$ elements and $K$ nodes (Fig. 5).

Using this approximation scheme, Eq. (6) is written at the centroid of each element, which yields:

$$
\frac{1}{\frac{1}{3} \sum_{k=1}^{3} \sqrt{g\left(\boldsymbol{x}_{k}\right)}} \sum_{k=1}^{3}\left[\sqrt{g\left(\boldsymbol{x}_{k}\right)} h\left(x_{k}\right) \sigma^{\alpha \beta}\left(\boldsymbol{x}_{k}\right) \boldsymbol{g}_{\alpha}\left(\boldsymbol{x}_{k}\right) \frac{d \varphi_{k}}{d \xi^{\beta}}\right]+p \frac{1}{3} \sum_{k=1}^{3} \boldsymbol{n}\left(\boldsymbol{x}_{\boldsymbol{k}}\right)=\mathbf{0}
$$

where $\frac{d \varphi_{k}}{d \xi^{\beta}}$ are the shape function derivatives at the centroid of the element and where the Einstein summation convention still applies for indexes $\alpha$ and $\beta$. Eq. (7) is then projected into the GCS and the procedure is repeated for each triangular element. A linear system of $3 N$ equations is produced. It contains $3 K$ unknowns which are the 3 components of the Cauchy stress tensor in the local covariant basis at the $K$ nodes of the mesh. A convergence study showed that a mesh with $N=1203$ elements and $K=644$ nodes was a good compromise between precision and time of calculation.

The system was completed by a set of equations on the boundaries of the tested area, where it was assumed: 


$$
(\boldsymbol{\sigma} \cdot \boldsymbol{j}) \cdot \boldsymbol{n}=0
$$

$$
(\boldsymbol{\sigma} \cdot \boldsymbol{j}) \cdot \boldsymbol{i}=0
$$

185

where $\boldsymbol{i}, \boldsymbol{j}, \boldsymbol{n}$ defines a local basis at the boundaries (Fig. 5-b) with $i$ is tangent to the boundary, $\boldsymbol{n}$ is an outward unit normal vector to the surface and $\boldsymbol{j}=\boldsymbol{n} \otimes \boldsymbol{i}$ is chosen to make the local coordinate system right-handed. Along the boundaries, Eq. (8) sets the traction vector perpendicular to , allowing in-plane tractions only and Eq. (9) sets the traction vector perpendicular to $i$, allowing no shear on the boundary. The resultant boundary traction automatically balances the total pressure applied on the wall due to the local equilibrium equation (Eq. (6)) written for each element. The final over-determined linear system of equations was solved in the least-squares sense.

The calculated components of the stress tensor are finally projected in the orthonormal local coordinate system $(\operatorname{LCS})\left(\boldsymbol{e}_{1}, \boldsymbol{e}_{2}, \boldsymbol{e}_{3}\right)$ defined such that:

$$
\begin{gathered}
\boldsymbol{e}_{3}=\boldsymbol{n} \\
\boldsymbol{e}_{2}=\frac{\boldsymbol{g}_{2}}{\left\|\boldsymbol{g}_{2}\right\|} \\
\boldsymbol{e}_{1}=\boldsymbol{e}_{2} \otimes \boldsymbol{e}_{3}
\end{gathered}
$$

where $\boldsymbol{n}$ is again the outward unit normal to the surface.

The stress was analyzed at three locations:

- NodeMAX: node with the largest stress eigenvalue

- NodeTOP: node at the top of the inflated membrane

- NodeRUP: node where rupture initiates 
At NodeMAX and NodeTOP locations, the largest eigenvalue of the Cauchy stress tensor (largest principal stress) were found and denoted $\sigma^{\operatorname{Max}}$ and $\sigma^{T o p}$, respectively. At NodeRUP, the stress in the direction perpendicular to the crack that occurs at rupture was computed:

$$
\sigma^{R u p}=\left(\boldsymbol{\sigma} \cdot \boldsymbol{q}_{\theta}\right) \cdot \boldsymbol{q}_{\theta}
$$

where $\boldsymbol{q}_{\theta}$ is the unit vector perpendicular to the rupture (Fig. 8c). It is derived for each specimen using the images obtained from the DIS-C system at the moment of the rupture. Using a custom MatLab ${ }^{\circledR}$ code, a series of points were manually placed on an image of the ruptured edge. A linear regression was then performed using those points and the angle between the fit line and the horizontal axis was calculated.

\section{Finite Element Validation Study}

Using a mesh size of $N=1203$ elements and $K=644$ nodes, a validation analysis was performed (see Appendix A for details). The stress distributions obtained from a finite element analysis (FEA) were defined as reference values and compared with the stress distributions obtained using the present approach.

\section{Thickness Evolution}

At every pressure step, the current thickness of each element was calculated. The aneurysmal tissue was modeled as incompressible membrane therefore the following relationship holds between the initial thickness, $h_{0}$, and the current thickness, $h$. 


$$
h=\frac{h_{0}}{F_{11} F_{22}-F_{21} F_{12}}
$$

We note that the ex vivo thickness, $h_{0}$, was assumed to be initially homogeneous and that $F_{11}, F_{22}$, $F_{21}$ and $F_{12}$ are the components of the deformation gradient tensor (Eq. (3)).

\section{Laplace's Law}

Laplace's Law (Peterson et al., 1960; Humphrey 2002) was used to calculate a global estimate of the ultimate stress for each ATAA layer by assuming the sample was a hemisphere

$$
\sigma^{L a p}=\frac{p r}{2 h}
$$

where $p$ was the inflation pressure, $r$ was the radius of curvature estimated using a least-squares surface fitting of the inflated shape, and $h$ was the average current thickness of the elements in the mesh.

\section{RESULTS}

The stress distributions obtained from the FEA simulation (Fig. 6-a) were compared with the stress distributions obtained using the present approach (Fig. 6-b). The mean absolute error (Fig. 6-c) was calculated revealing that the largest errors occurred at the boundaries. Ignoring the elements at the boundaries, the average error was significantly reduced to $0.8 \%, 1.4 \%$, and $0.8 \%$ for $\sigma_{11}, \sigma_{22}$, and $\sigma_{12}$, respectively (Fig. 6-d). This showed that the stress estimates contain some errors along the border due to the assumed boundary conditions but these errors vanish rapidly away from the border. For this reason, only the tests where the rupture occurred at a distance of more than three 
elements away from the border were included in this study.

Using the approach we have presented, the components of the Cauchy stress tensor were calculated at every node for each $3 \mathrm{kPa}$ pressure step until the sample ruptured (Fig. 7-a). The displacement (Fig. 7-b) and strain fields (Fig. 7-c) used to calculate the stress and thickness evolution are also shown.

In Table 2 we report the three components of the Cauchy stress tensor. Our results (mean \pm std) for $\sigma_{11}$ were $1.18 \pm 0.64 \mathrm{MPa}$ at NodeMAX, $1.12 \pm 0.64 \mathrm{MPa}$ at NodeTOP and $1.06 \pm 0.59 \mathrm{MPa}$ at NodeRUP. The values for $\sigma_{22}$ were $1.21 \pm 0.80 \mathrm{MPa}$ at NodeMAX, $1.17 \pm 0.79 \mathrm{MPa}$ at NodeTOP and $1.05 \pm 0.71 \mathrm{MPa}$ at NodeRUP.

In Fig. 8-a, we show the thickness distribution (Eq. (12)) one pressure step before rupture for five tests. For each of the samples thick (dark red) and thin (dark blue) regions can be identified. The locations of NodeMAX, NodeTOP, and NodeRUP for these five tests are also shown in Fig. 8-b. Contrary to the generally accepted theory that the rupture occurs at the location of the maximum stress, the experimental results show that rupture often initiates at a different location (NodeRUP), possibly due to the non-homogeneous strength of the tissue. An image of the ruptured layer is shown in Fig. 8-c, where the magenta points and the blue regression line were used to determine the rupture angle, $\theta$.

Table 3 and Fig. 9 summarize the three ultimate stress values $\left(\sigma^{\text {Max }}, \sigma^{\text {Top }}\right.$, and $\left.\sigma^{\text {Rup }}\right)$ calculated at their corresponding locations (NodeMAX, NodeTOP and NodeRUP) compared with $\sigma^{\text {Lap }}$ (Eq. (13)). For the six adventitia layers, the average stress values (mean \pm std) were $1.49 \pm 1.06 \mathrm{MPa}, 1.76 \pm 1.07$ $\mathrm{MPa}, 1.69 \pm 1.10 \mathrm{MPa}$, and $1.46 \pm 1.03 \mathrm{MPa}$ for $\sigma^{L a p}, \sigma^{M a x}, \sigma^{T o p}$, and $\sigma^{\text {Rup }}$, respectively. For the remaining nine media layers, the average stress values were found to be $0.78 \pm 0.26 \mathrm{MPa}, 1.01 \pm 0.36$ 
$\mathrm{MPa}, 0.95 \pm 0.31 \mathrm{MPa}$, and $0.78 \pm 0.20 \mathrm{MPa}$ for $\sigma^{\operatorname{Lap}}, \sigma^{\text {Max }}, \sigma^{\text {Top }}$, and $\sigma^{\text {Rup }}$, respectively. The four calculated ultimate stress values were higher for the adventitia layers, confirming its role of structural support of the artery (Fung, 1993).

\section{DISCUSSION}

\section{Comparison with Existing Literature}

Other investigators performing inflation tests have reported rupture stresses between 0.751 and 1.75 MPa (Kim et al., 2012, Mohan and Melvin, 1983, Marra et al., 2006). In the present study the rupture stress, $\sigma^{\text {Rup }}$, was on average $1.46 \mathrm{MPa}$ for the adventitia layers and $0.72 \mathrm{MPa}$ for the media layers. The results obtained from our analysis were reasonable and lie within the range of reported values in the literature. It must be noted that our results were twice as large of those of Kim et al. (2012) who found 0.751 MPa for adventitia layers and 0.39 MPa for media layers. This can be explained by the different methods used to calculate the rupture stress. While Kim et al. (2012) assumed a constant thickness throughout the inflation, the present method was capable of estimating the thickness evolution of the sample (Eq. (12)). Based on the large changes in thickness observed in the samples (Fig. 10), it was expected that our values would be significantly larger than those reported by Kim et al. (2012).

\section{Comparison of the Ultimate Stress at Different Locations}

The stress found using Laplace's Law, $\sigma^{\text {Lap }}$, in Eq. (13) was considered a global estimate of the rupture stress, since it was computed using a global radius of curvature and the mean thickness of the inflated ATAA layer. A comparison between this global stress value and the calculated local stress values, $\sigma^{\text {Max }}, \sigma^{\text {Top }}$, and $\sigma^{R u p}$, was done as the majority of published studies have not calculated local stress distributions. The stress calculated from Laplace's Law was frequently smaller than the 
other local stress values. The difference can likely be explained by differences in the thickness calculation. On the one hand Laplace's Law uses the average current thickness of the entire inflated aortic layer while the three local stress values use the current local thickness of the element where the node concerned was located.

\section{Detection of Weakened Zones in the Tissue}

In every test rupture was preceded by significant local deformation and reduction of the thickness. This phenomenon was clearly illustrated in Fig. 8, where local thinning was observed at the rupture location. Occasionally the maximum stress value was located in the weakened area, but more frequently it was located elsewhere. This led us to hypothesize that the ATAA layers had weakened regions that caused the localized thinning of the layer during the inflation test. When observing the evolution of the ATAA layer thickness (Fig. 10), the region where the rupture was most likely to occur could be observed many stages before the rupture. Moreover, the orientation of the rupture always appeared in the same direction as the thickness heterogeneity in the inflated ATAA layer.

\section{Main Sources of Variability}

It was noticed that test number 2 , an adventitia layer, had by far the highest ultimate stress values. Possibly explained because this layer was the thinnest of all the tissue samples and the donor patient was 36 years old, which made him by far the youngest patient donor (mean age: 66 years).

\section{Limitations}

\section{a) Comparison with healthy tissue}

Due to the difficulty of obtaining healthy ascending aortic specimens, there was no comparison between healthy aorta and ATAA specimens. As many authors have noticed (Choudhury et al., 2008; Cinthio et al., 2006; Prehn et al., 2009), this comparison can help understanding the causes of the pathology. 
b) Initial thickness measurement

The measurement of the ex vivo initial thickness $h_{0}$ of the ATAA tissue was an average estimate of the thickness of the tissue. Measuring the thickness of the specimen at various locations in the tissue was precluded as the sharp shape of the caliper can easily penetrate the soft tissue and damage the tissue. The tests method could be further improved in the future by incorporating a technique capable of capturing the location dependent thickness of the tissue. Other techniques such as, for example, a PC-based video extensometer (Sommer et al., 2008) or a non-contact laser beam micrometer (lliopoulos et al., 2009) could be used to measure the thickness of the aortic tissue at multiple locations.

\section{c) Effect of the loading conditions}

A finite element study was undertaken to show that the traction boundary conditions used in our simulation (Eqs. 9-10) only minimally affected the stress calculations in the center region of the specimen. Due to boundary effects, the present approach is limited to characterizing rupture phenomenon occurring far from the boundaries. In the future it would be useful to improve the precision by implementing an approach similar to Zhao (2009) who defined a boundary-effect-free region where the calculated stress distribution remains invariant.

\section{d) Pure membrane assumption}

Using the present approach, the average stress across the thickness of the inflated ATAA layer was calculated. The assumption of a pure membrane behavior is justified when the concerned tissue is subjected to tensile extension, and is physically thin enough so the transverse shear and the acrossthickness stress variation are safely ignored (Horgan and Saccomandi 2003, Lu et al. 2008). Based on the validation analysis (Appendix A), the stress distribution calculated using the present approach was in very good agreement with the average stress distribution calculated between the outer and 
inner surface using Abaqus ${ }^{\circledR}$ software. This indicates that the pure membrane assumption does not affect the reconstruction of this average stress across the thickness.

\section{CONCLUSIONS}

In this manuscript, we have used a straight forward approach to investigate the in vitro rupture behavior of ATAA layer during an inflation test. The main advantage of our approach was that local stress field for the ATAA layer was obtained without requiring any material properties. Our results showed that rupture in the ATAA inflated layers was more prone to occur in regions where the layer was weakened. The majority of the time, rupture occurs where the thickness of the layer has been reduced the most. Using maps of the local thickness as a function of pressure one can easily predict the rupture location. Future studies must be conducted to determine if the localized thinning observed in these experiments can also be observed in vivo using techniques such as magnetic resonance imaging.

\section{ACKNOWLEDGEMENTS}

The authors would like to acknowledge the National Council on Science and Technology of Mexico (CONACYT) for funding Mr. Romo's scholarship. We also would like to thank Dr. Frances Davis for her helpful suggestions to improve the quality of the paper.

\section{CONFLICT OF INTEREST}


None

\section{REFERENCES}

Adham, M., Gournier, J., Favre, J., De La Roche, E., Ducerf, C., Baulieux, J., Barral, X., Pouyet, M., 1996. Mechanical characteristics of fresh and frozen human descending thoracic aorta. Journal of Surgical Reaserch, 64(1), 32-34.

Avril, S., Badel, P., Duprey, A., 2010. Anisotropic and hyperelastic identification of in vitro human arteries from full-field measurements. Journal of Biomechanics 43(15), 2978-2985.

Choudhury, N., Bouchot, O., Rouleau, L., Tremblay, D., Cartier, R., Butany, J., Mongrain, R., Leask, R., 2008. Local mechanical and structural properties of healthy and diseased human ascending aorta tissue, Cardiovascluar Pathology 18, 83-91.

Cinthio, M., Ahlgren, A., Bergkvist, J., Jansson, T., Persson, H., Lindstrom, K., 2006. Longitudinal mouvements and resulting shear strain of the arterial wall. American Journal of Physiology Heart and Circulatory Physiology 291, H394-H402.

Clouse, W., Hallett, J., Schaff, H., Gayari, M., Ilstrup, D., Melton, L., 1998. Improved prognosis of thoracic aortic aneurysms: a population-based study. Journal of the American Medical Association 280, 1926-1929.

Duprey, A., Khanafer, K., Schlicht, M., Avril, S., Williams, D., Berguer, R., 2010. In vitro characterization of physiological and maximum elastic modulus of ascending thoracic aortic aneurysms using uniaxial tensile testing. European Journal of Vascular and Endovascular Surgery 39, 700-707.

Fung Y., 1993. Biomechanics: mechanical properties of living tissues. Springer, New York.

Garcia-Herrera, C., Atienza, J., Rojo, F., Claes, E., Guinea, G., Celentano, D., Garcia-Montero, C., Burgos, R., 2012. Mechanical behaviour and rupture of normal and pathological human ascending aortic wall. Medical \& Biological Engineering \& Computing 50, 559-566.

Grédiac, M., Pierron, F., Avril, S., Toussaint, E., 2006. The virtual fields method for extracting constitutive parameters from full-field measurements: a review. Strain 42(4), 233-253.

Green, A., and Adkins, J., 1970. Large elastic deformations. Clarendon Press, Oxford.

He, C.M., Roach, M.R., 1994. The composition and mechanical properties of abdominal aortic aneurysms. Journal of Vascular Surgery 20, 6-13.

Holzapfel, G., Gasser, T., Ogden, R., 2000. A New Constitutive Framework for Arterial Wall Mechanics and a Comparative Study of Material Models. Journal of Elasticity, 61(1), 1-48.

Horgan, C., and Saccomandi, G., 2003. A description of arterial wall mechanics using limiting chain extensibility constitutive models. Biomechanics and modeling in mechanobiology 1(4), 25166.

Humphrey, J., 2002. Cardiovascular solid mechanics: cells, tissues, and organs. Springer, New York.

Iliopoulos, D., Deveja, R., Kritharis, E., Perrea, D., Sionis, G., Toutouzas, K., Stefanadis, C., Sokolis, D., 2009. Regional and directional variations in the mechanical properties of ascending thoracic aortic aneurysms. Medical Engineering \& Physics 31, 1-9.

Isselbacher, E., 2005. Thoracic and abdominal aortic aneurysms. Circulation 111, 816-828.

Kim, J., Avril, S., Duprey, A., Favre, J., 2012. Experimental characterization of rupture in human aortic aneurysms using a full-field measurements technique. Biomechanics and Modeling in Mechanobiology 6, 841-853. 
Lee, J., Langdon, S., 1996. Thickness measurement of soft tissue biomaterials: a comparison of five methods. Journal of Biomechanics 29(6), 829-832.

Lu, J., Zhou, X., Raghavan, M., 2008. Inverse method of stress analysis for cerebral aneurysms. Biomechanics and Modeling in Mechanobiology 7, 477-486.

Marra, S., Kennedy, F., Kinkaid, J., Fillinger, M., 2006. Elastic and rupture properties of porcine aortic tissue measured using inflation testing. Cardiovascular Engineering 6(4), 123-131.

Mohan, D., Melvin, J., 1982. Failure properties of passive human aortic issue. I-uniaxial tension tests. Journal of Biomechanics 15, 887-902.

Mohan, D., Melvin, J., 1983. Failure properties of passive human aortic tissue. II-biaxial tension tests. Journal of Biomechanics 16, 31-44.

Naghdi, P., 1972. The Theory of Shells and Plates. In: C. Truesdell (ed.) Encyclopedia of Physics. Springer, New York.

Peterson, L., Jenesen, R., Parnell, J., 1960. Mechanical properties of arteries in vivo. Circulation Research 8, 622-639.

Prehn, J., Herwaarden, J., Vincken, K., Verhagen, H., Moll, F., Bartels, L., 2009. Asymmetric aortic expansion of the aneurysm neck: Analysis and visualization of shape changes with electrocardiogram-gated magnetic resonance imaging. Journal of Vascular Surgery 49, 13951402.

Sommer, G., Gasser, T., Regitnig, P., Auer, M., Holzapfel, G., 2008. Dissection properties of the human aortic media: an experimental study. ASME Journal of Biomechanical Engineering 130, 021007-1 - 021007-12.

Vorp, D., Schiro, B., Ehrlich, M., Juvonen, T., Ergin, M., Griffith, B., 2003. Effect of aneurysm on the tensile strength and biomechanical behavior of the ascending thoracic aorta. The Annals of Thoracic Surgery 75(4), 1210-1214.

Zhao, X., 2009. Pointwise identification of elastic properties in nonlinear heterogeneous membranes, and application to soft tissues. Dissertation, University of lowa. http://ir.uiowa.edu/etd/222. 


\section{List of Tables}

Table

1 Demographic information for the collected ATAA specimens.

2 Components of the Cauchy stress tensor reported at the NodeMAX, NodeTOP and NodeRUP locations (in $\mathrm{MPa}$ ). Test No. 1 to 6 were adventitia layers and Test No. 7 to 15 were media layers.

3 Comparison between four different ultimate stress values calculated at different locations within the same tissue. Test No. 1 to 6 were adventitia layers and Test No. 7 to 15 were media layers. 


\section{List of Figures}

Figure

1 ATAA specimen preparation for the inflation test

2 View of the experimental set-up and the inflation of the ATAA layer through the left and right cameras of the DIS-C system. An image is recorded every loading stage defined at $3 \mathrm{kPa}$, for the duration of the test. Note that the acrylic protector is used to prevent water from reaching the cameras when the specimen bursts.

3 Reconstructed shape of the ATAA layer at the final inflation stage. The 3D coordinates of each material point were used to reconstruct the shape.

$4 \quad$ Schematic of the kinematics and base vectors.

5 Discretization of the surface. The unchanged mesh is deformed from a) the initial to b) the current configuration. For one boundary element the local $(i, j, n)$ Cartesian frame used to define the boundary conditions is shown.

6 Top view of the element by element comparison between stress fields calculated by a) the FEA simulation (reference) and b) our approach. The absolute error (in MPa) between a) and b) is presented in c) and in d) where the boundary elements are neglected.

7 The a) stress field $\left(\sigma_{11}\right)$, b) displacement field $\left(U_{3}\right)$ and c) strain field $\left(E_{22}\right)$ for three ATAA specimens all at a pressure of $0.027 \mathrm{MPa}$.

8 ATAA rupture. For each test, a) the color map of the thickness measurement, b) the deformed mesh $\left(O=\right.$ NodeMAX, $\mathbf{A}=$ NodeTOP, $\boldsymbol{t}=$ NodeRUP) and c) the rupture picture where $q_{\theta}$ is the unit vector perpendicular to the rupture.

9 Four different ultimate stresses for each of the 15 ATAA samples where $\sigma^{\text {Lap }}$ is the Laplace stress calculated from Eq. (13), $\sigma^{\operatorname{Max}}$ is the maximum principal stress, $\sigma^{T o p}$ is the maximum principal stress at the node of the top, and $\sigma^{R u p}$ is the rupture stress calculated from Eq. (11).

10 Local thickness evolution (Eq. (12)) in mm. for one representative ATAA sample (Test No. 14). Top view from the initial stage $(0.003 \mathrm{MPa})$ until the final stage $(0.057 \mathrm{MPa})$ and the image captured by the DIS-C system at rupture are presented. 
TABLE 1. Demographic information for the collected ATAA specimens.

\begin{tabular}{c|cccc}
\hline Test No. & Layer Type & Sex/Age & Diameter before surgery $(\mathbf{m m})$ & Ex vivo thickness $(\mathbf{m m})$ \\
\hline $\mathbf{1}$ & adventitia & $\mathrm{M} / 67$ & 50 & 1.18 \\
$\mathbf{2}$ & adventitia & $\mathrm{M} / 36$ & 50 & 0.51 \\
$\mathbf{3}$ & adventitia & $\mathrm{M} / 55$ & 53 & 0.79 \\
$\mathbf{4}$ & adventitia & $\mathrm{M} / 81$ & 54 & 0.64 \\
$\mathbf{5}$ & adventitia & $\mathrm{M} / 76$ & 52 & 0.62 \\
$\mathbf{6}$ & adventitia & $\mathrm{M} / 71$ & 0.55 \\
$\mathbf{7}$ & media & $\mathrm{M} / 70$ & 48 & 0.89 \\
$\mathbf{8}$ & media & $\mathrm{M} / 67$ & 63 & 0.68 \\
$\mathbf{9}$ & media & $\mathrm{M} / 54$ & 50 & 0.98 \\
$\mathbf{1 0}$ & media & $\mathrm{M} / 55$ & 60 & 1.09 \\
$\mathbf{1 1}$ & media & $\mathrm{F} / 76$ & 53 & 1.15 \\
$\mathbf{1 2}$ & media & $\mathrm{M} / 81$ & 55 & 0.91 \\
$\mathbf{1 3}$ & media & $\mathrm{M} / 68$ & 54 & 1.02 \\
$\mathbf{1 4}$ & media & $\mathrm{M} / 69$ & 59 & 1.09 \\
$\mathbf{1 5}$ & media & $\mathrm{M} / 71$ & 51 & 1.04 \\
\hline
\end{tabular}


TABLE 2. Components of the Cauchy stress tensor reported at the NodeMAX, NodeTOP and NodeRUP locations (in MPa). Test No. 1 to 6 were adventitia layers and Test No. 7 to 15 were media layers.

\begin{tabular}{|c|c|c|c|c|c|c|c|c|c|}
\hline \multirow[b]{2}{*}{ Test No. } & \multicolumn{3}{|c|}{ NodeMAX } & \multicolumn{3}{|c|}{ NodeTOP } & \multicolumn{3}{|c|}{ NodeRUP } \\
\hline & $\sigma_{11}$ & $\sigma_{22}$ & $\sigma_{12}$ & $\sigma_{11}$ & $\sigma_{22}$ & $\sigma_{12}$ & $\sigma_{11}$ & $\sigma_{22}$ & $\sigma_{12}$ \\
\hline 1 & 1.124 & 1.091 & -0.036 & 0.681 & 0.842 & -0.098 & 1.128 & 1.062 & -0.005 \\
\hline 2 & 3.066 & 3.812 & -0.065 & 3.035 & 3.778 & -0.064 & 2.954 & 3.527 & 0.084 \\
\hline 3 & 1.233 & 1.613 & -0.011 & 1.246 & 1.554 & 0.023 & 0.977 & 0.949 & 0.189 \\
\hline 4 & 0.938 & 0.853 & 0.001 & 0.922 & 0.863 & -0.002 & 0.922 & 0.795 & 0.012 \\
\hline 5 & 1.964 & 1.642 & 0.050 & 1.920 & 1.647 & 0.020 & 1.699 & 1.419 & -0.042 \\
\hline 6 & 1.035 & 1.019 & -0.046 & 1.035 & 1.019 & -0.046 & 0.920 & 0.933 & -0.108 \\
\hline 7 & 0.756 & 0.997 & 0.041 & 0.677 & 0.909 & 0.078 & 0.640 & 0.924 & 0.006 \\
\hline 8 & 1.764 & 1.654 & 0.097 & 1.617 & 1.573 & 0.077 & 1.120 & 0.913 & -0.051 \\
\hline 9 & 1.042 & 1.064 & -0.06 & 1.033 & 1.067 & -0.05 & 0.903 & 1.049 & -0.027 \\
\hline 10 & 1.308 & 1.007 & -0.012 & 1.042 & 1.038 & -0.028 & 1.174 & 0.927 & -0.042 \\
\hline 11 & 0.627 & 0.622 & -0.009 & 0.549 & 0.602 & -0.03 & 0.552 & 0.605 & -0.025 \\
\hline 12 & 0.631 & 0.630 & 0.076 & 0.664 & 0.633 & 0.042 & 0.655 & 0.626 & 0.040 \\
\hline 13 & 0.819 & 0.720 & -0.055 & 0.805 & 0.714 & -0.053 & 0.815 & 0.725 & -0.051 \\
\hline 14 & 0.728 & 0.866 & -0.018 & 0.800 & 0.858 & -0.016 & 0.791 & 0.805 & 0.0001 \\
\hline 15 & 0.805 & 0.601 & -0.037 & 0.79 & 0.588 & -0.044 & 0.714 & 0.546 & -0.041 \\
\hline Mean & 1.18 & 1.21 & -0.006 & 1.12 & 1.17 & -0.013 & 1.06 & 1.05 & -0.004 \\
\hline Std. & 0.64 & 0.80 & 0.05 & 0.64 & 0.79 & 0.05 & 0.59 & 0.71 & 0.06 \\
\hline
\end{tabular}


TABLE 3. Comparison between four different ultimate stress values calculated at different locations within the same tissue. Test No. 1 to 6 were adventitia layers and Test No. 7 to 15 were media layers.

\begin{tabular}{c|cccc}
\hline Test No. & $\boldsymbol{\sigma}^{\text {Lap }}$ (MPa) & $\boldsymbol{\sigma}^{\text {Max }}$ (MPa) & $\boldsymbol{\sigma}^{\text {Top }}(\mathrm{MPa})$ & $\boldsymbol{\sigma}^{\text {Rup }}$ (MPa) \\
\hline $\mathbf{1}$ & 0.9695 & 1.1481 & 0.8889 & 1.0719 \\
$\mathbf{2}$ & 3.5825 & 3.8183 & 3.7841 & 3.5269 \\
$\mathbf{3}$ & 1.1725 & 1.6134 & 1.5558 & 0.9755 \\
$\mathbf{4}$ & 0.8116 & 0.9385 & 0.9222 & 0.8265 \\
$\mathbf{5}$ & 1.5928 & 1.9724 & 1.9221 & 1.4644 \\
$\mathbf{6}$ & 0.8414 & 1.0752 & 1.0752 & 0.9335 \\
$\mathbf{7}$ & 0.7275 & 1.0049 & 0.9337 & 0.6412 \\
$\mathbf{8}$ & 1.4016 & 1.8214 & 1.6756 & 1.0057 \\
$\mathbf{9}$ & 0.8503 & 1.1148 & 1.1036 & 0.9309 \\
$\mathbf{1 0}$ & 0.8215 & 1.3086 & 1.0692 & 1.1733 \\
$\mathbf{1 1}$ & 0.4863 & 0.6346 & 0.6169 & 0.6015 \\
$\mathbf{1 2}$ & 0.5559 & 0.7074 & 0.6936 & 0.6286 \\
$\mathbf{1 3}$ & 0.7283 & 0.8438 & 0.8302 & 0.7259 \\
$\mathbf{1 4}$ & 0.8244 & 0.8687 & 0.8623 & 0.8028 \\
$\mathbf{1 5}$ & 0.6386 & 0.8121 & 0.7994 & 0.5891 \\
\hline \multirow{2}{*}{ Mean } & $\mathbf{1 . 0 6 6 9}$ & $\mathbf{1 . 3 1 2 1}$ & $\mathbf{1 . 2 4 8 8}$ & $\mathbf{1 . 0 5 9 8}$ \\
$\mathbf{S t d}$. & $\mathbf{0 . 7 5 7 3}$ & $\mathbf{0 . 7 9 7 9}$ & $\mathbf{0 . 7 9 3 3}$ & $\mathbf{0 . 7 2 3 6}$ \\
\hline
\end{tabular}




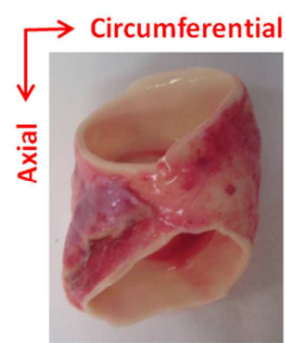

a) Excised tissue sample.

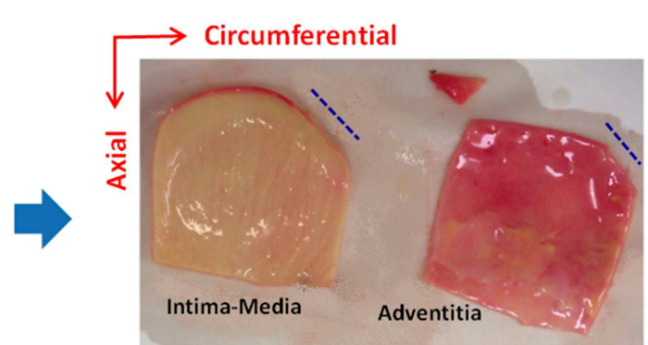

b) Separated aortic layers.

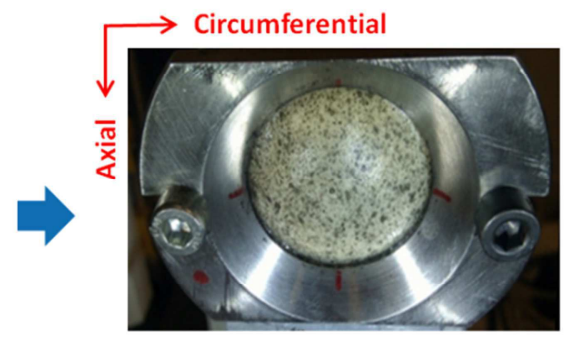

c) Aortic layer clamped in the inflation device.

Fig. 1. ATAA specimen preparation for the inflation test. 


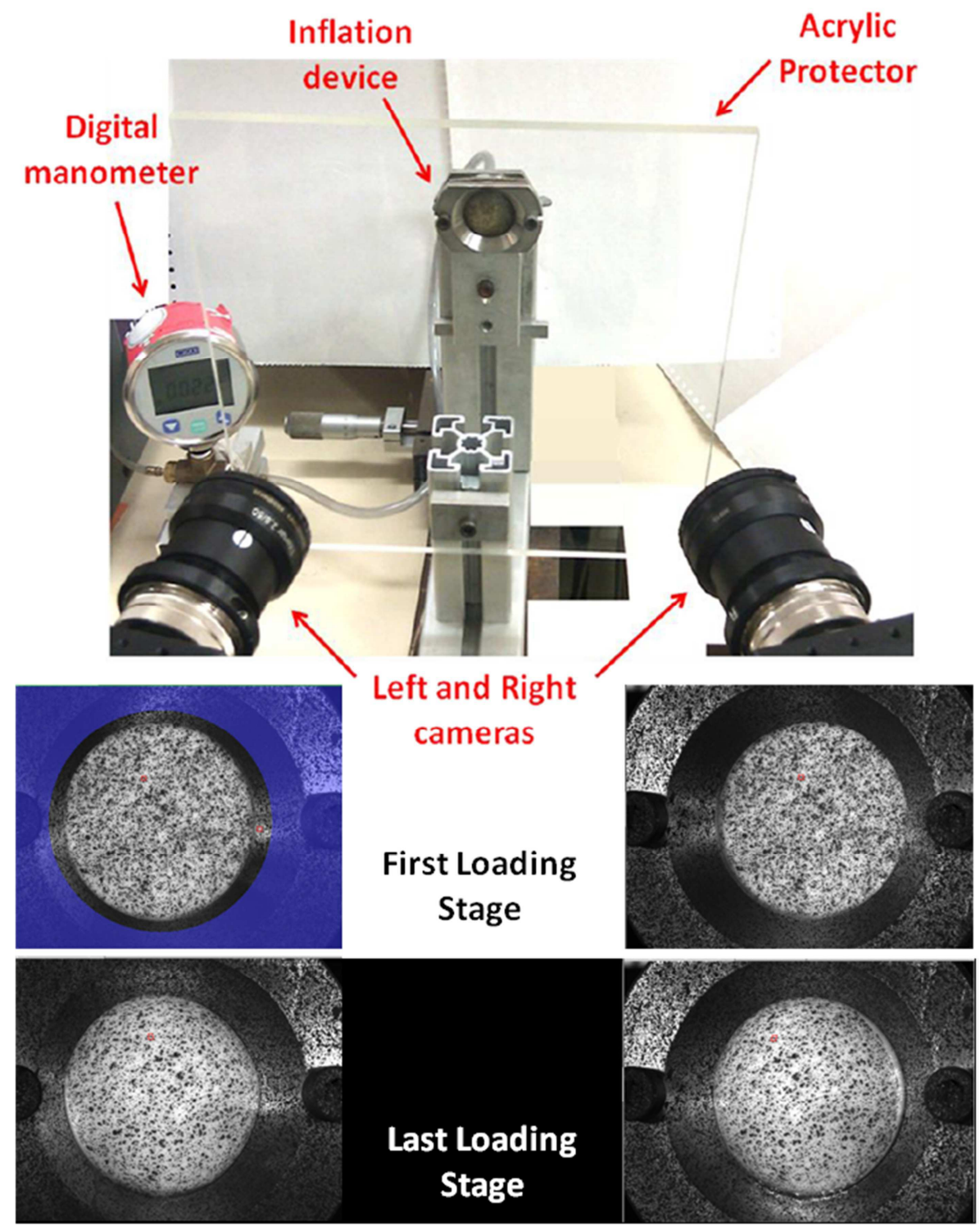

Fig. 2. View of the experimental set-up and the inflation of the ATAA layer through the left and right cameras of the DIS-C system. An image is recorded every loading stage defined at $3 \mathbf{k P a}$, for the duration of the test. Note that the acrylic protector is used to prevent water from reaching the cameras when the specimen bursts. 


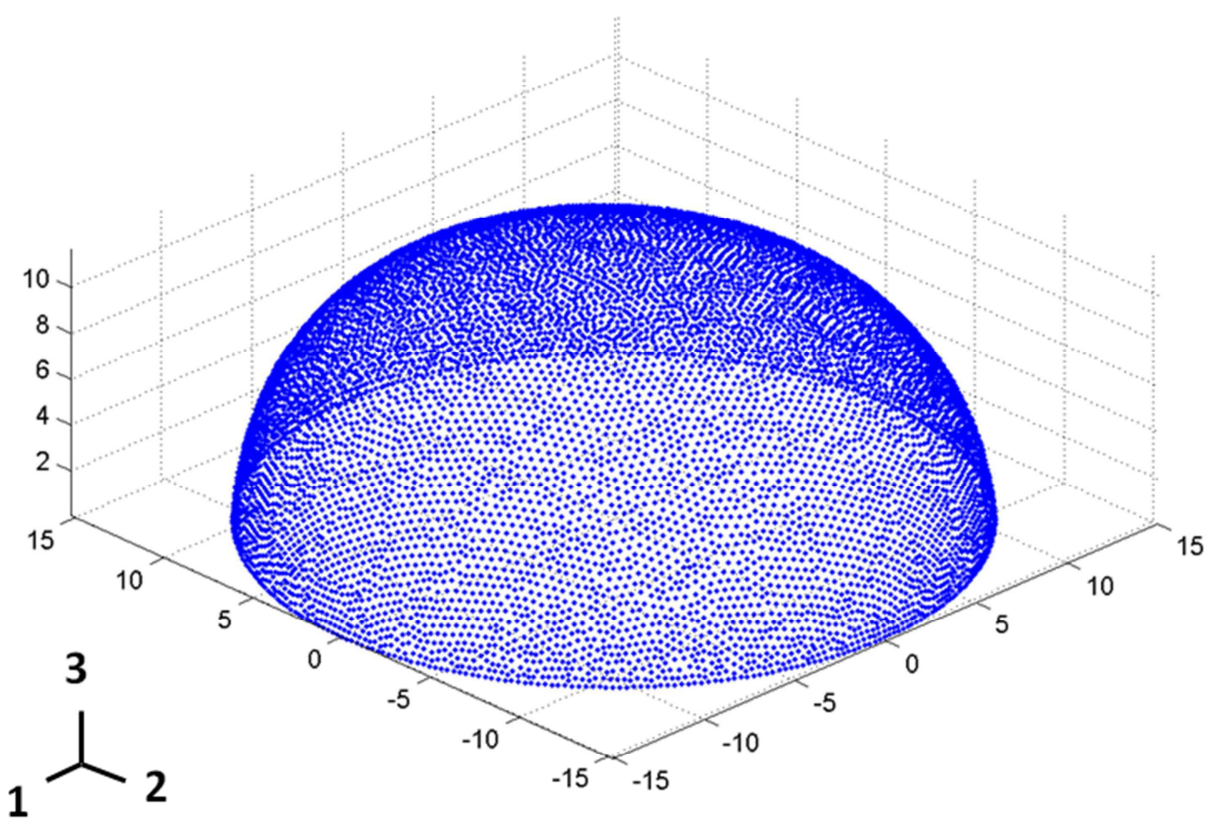

Fig. 3. Reconstructed shape of the ATAA layer at the final inflation stage. The 3D coordinates of each material point were used to reconstruct the shape. 


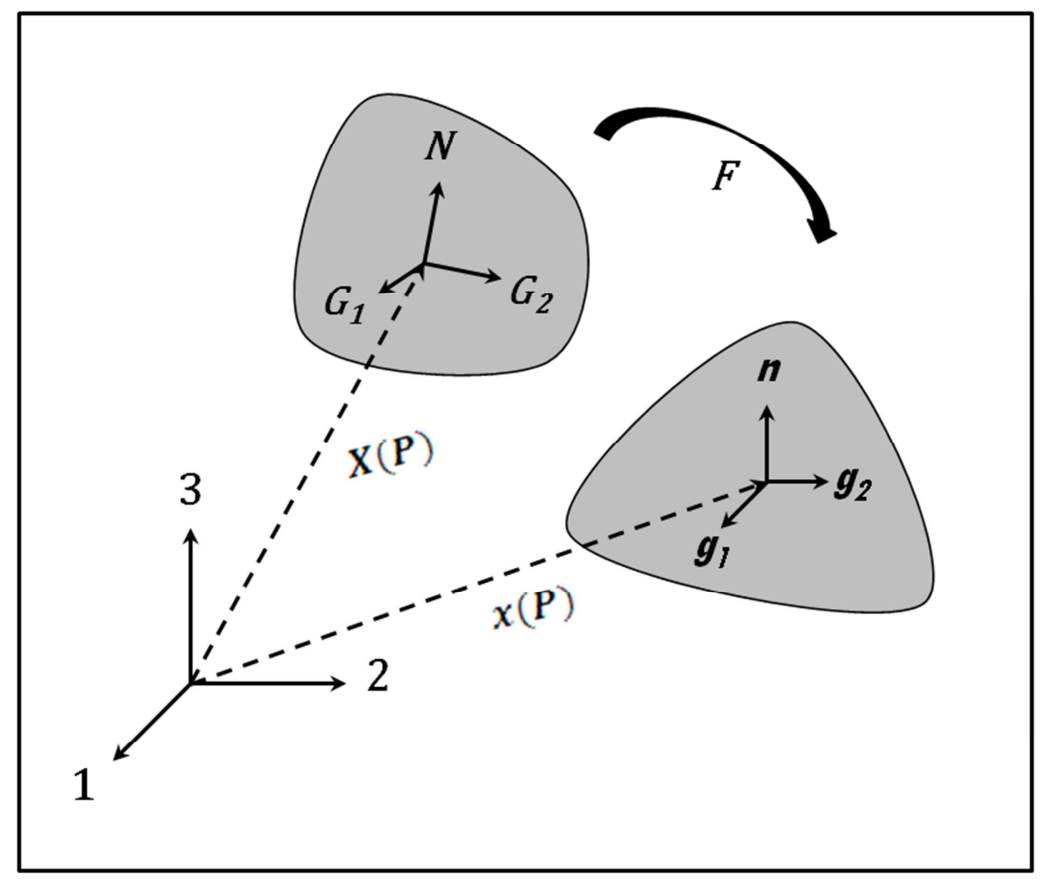

Fig. 4. Schematic of the kinematics and base vectors. 


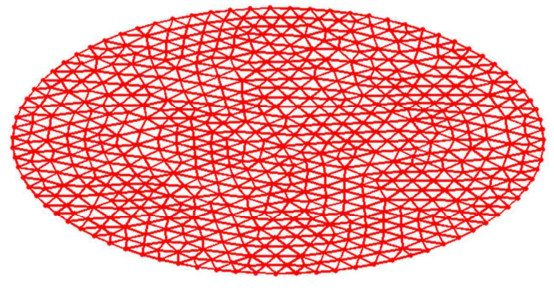

a)

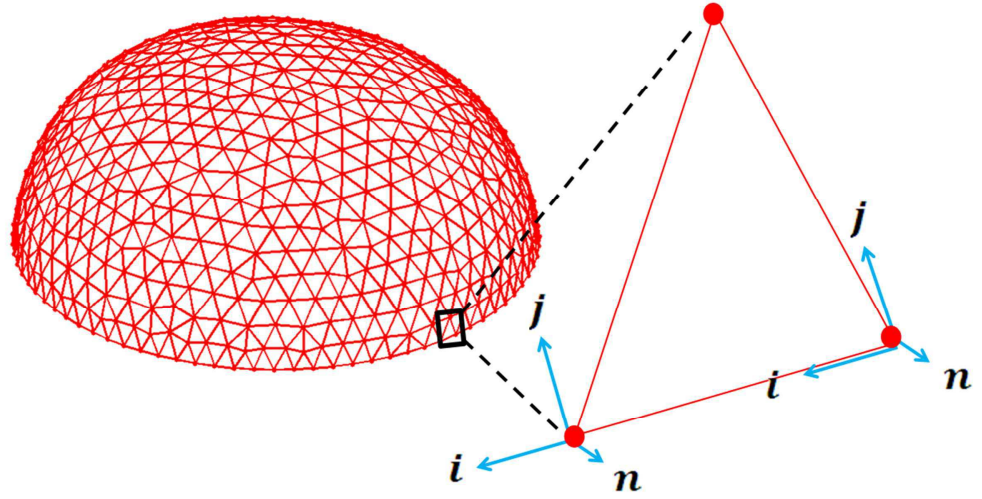

b)

Fig. 5. Discretization of the surface. The unchanged mesh is deformed from a) the initial to $b$ ) the current configuration. For one boundary element the local $(i, j, n)$ Cartesian frame used to define the boundary conditions is shown. 

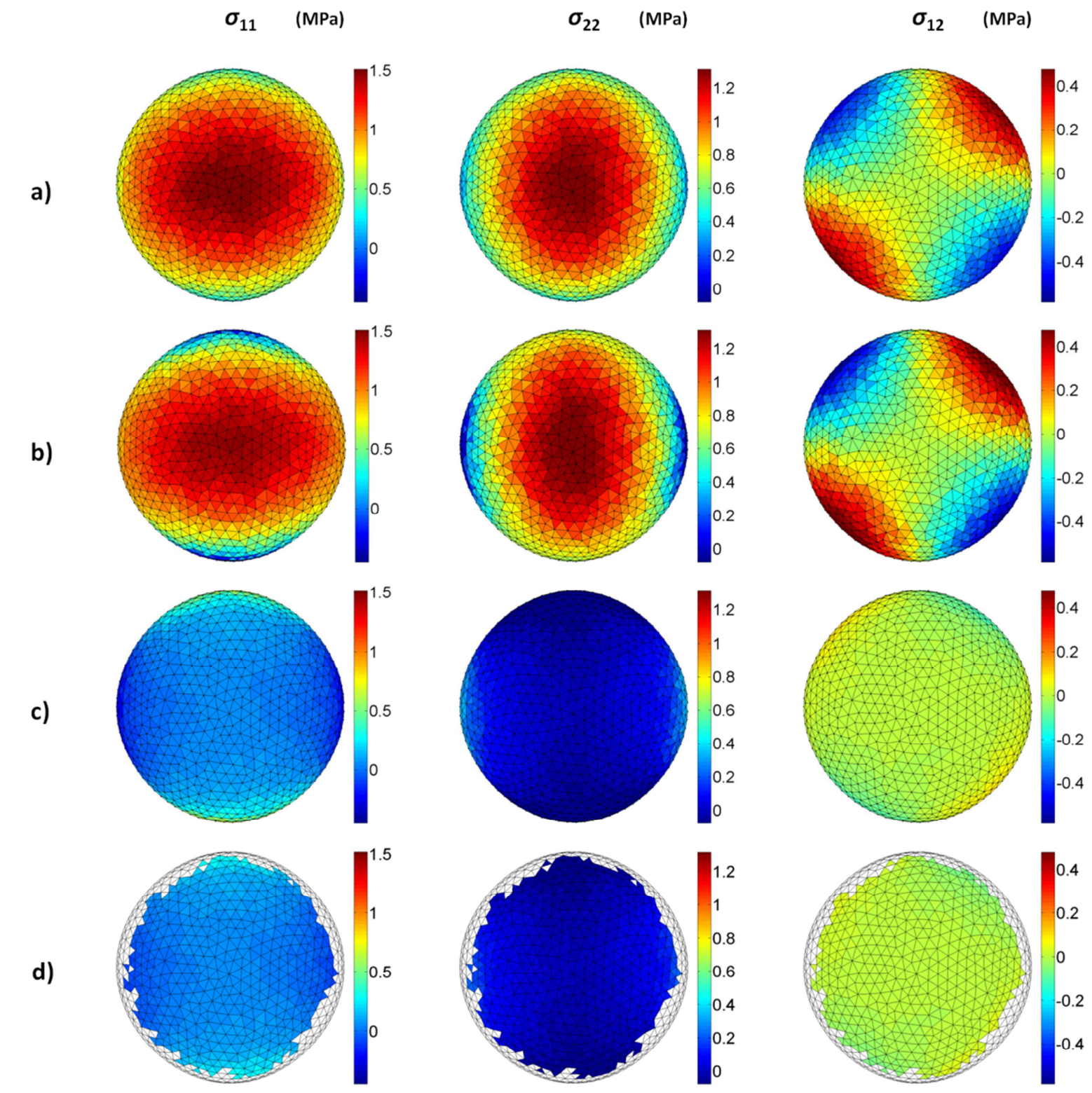

Fig. 6. Top view of the element by element comparison between stress fields calculated by a) the FEA simulation (reference) and b) our approach. The absolute error (in MPa) between a) and b) is presented in c) and in d) where the boundary elements are neglected. 

Test
a) Stress fields $\left(\sigma_{11}\right)$
b) Displacement fields $\left(U_{3}\right)$
c) Strain fields $\left(E_{22}\right)$

No.

1

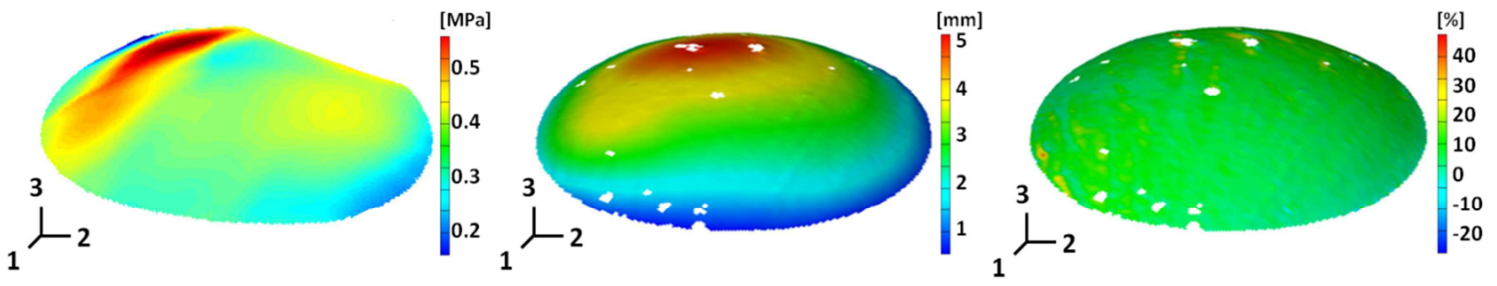

9
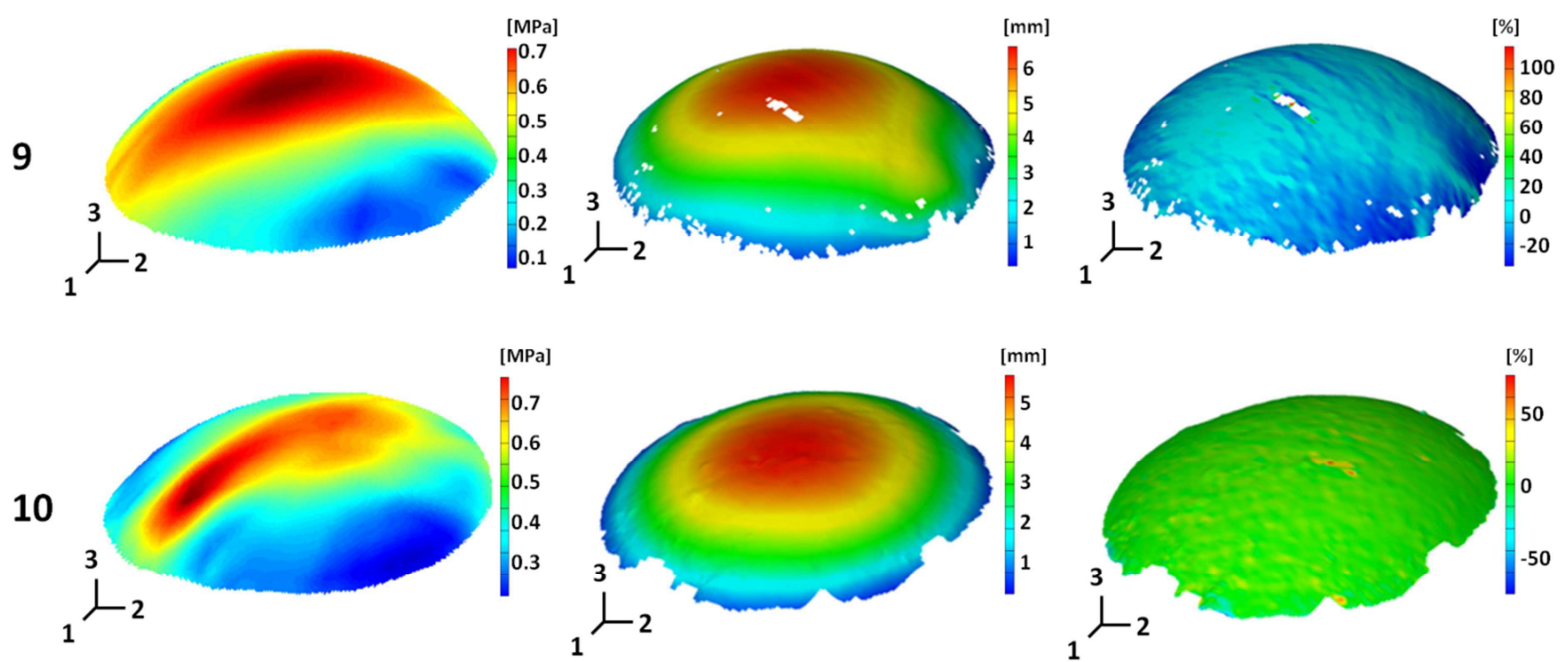

Fig. 7. The a) stress field $\left(\sigma_{11}\right)$, b) displacement field $\left(U_{3}\right)$ and c) strain field $\left(E_{22}\right)$ for three ATAA specimens all at a pressure of $0.027 \mathrm{MPa}$. 
Test a) Color map thickness ( $\mathrm{mm}$ )

No.

1

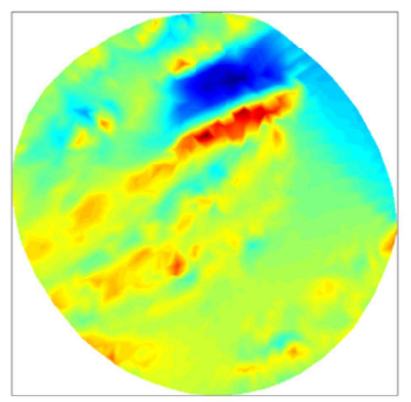

9
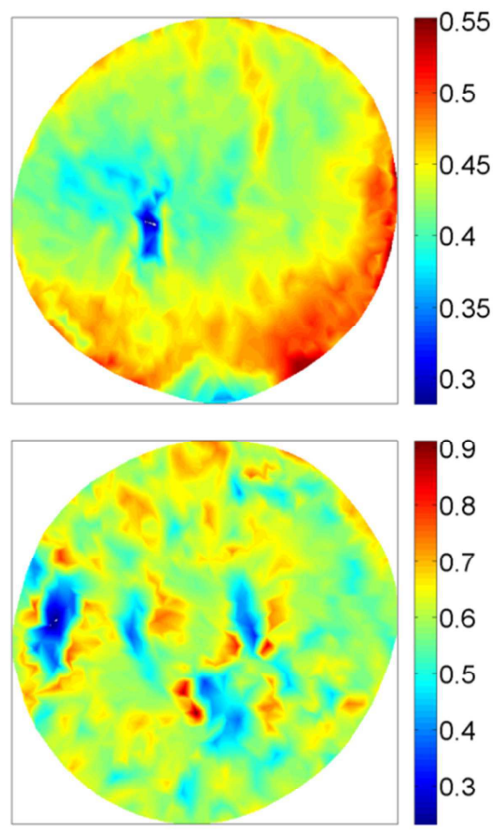

11

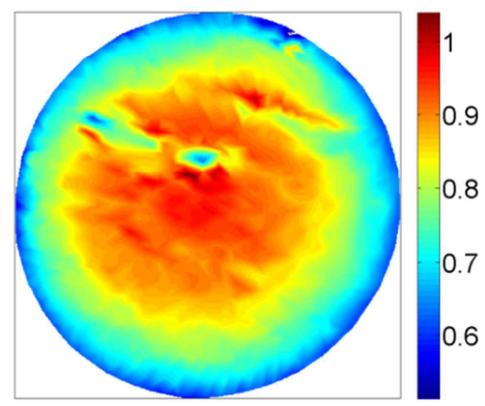

14

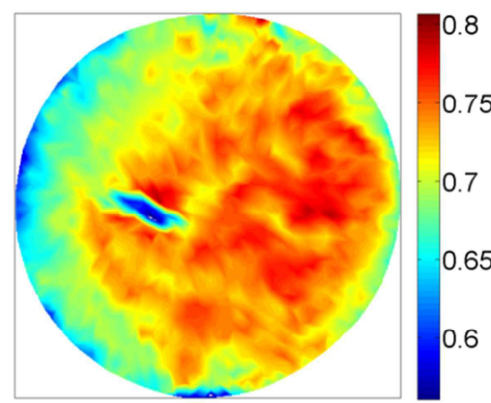

b) Deformed mesh
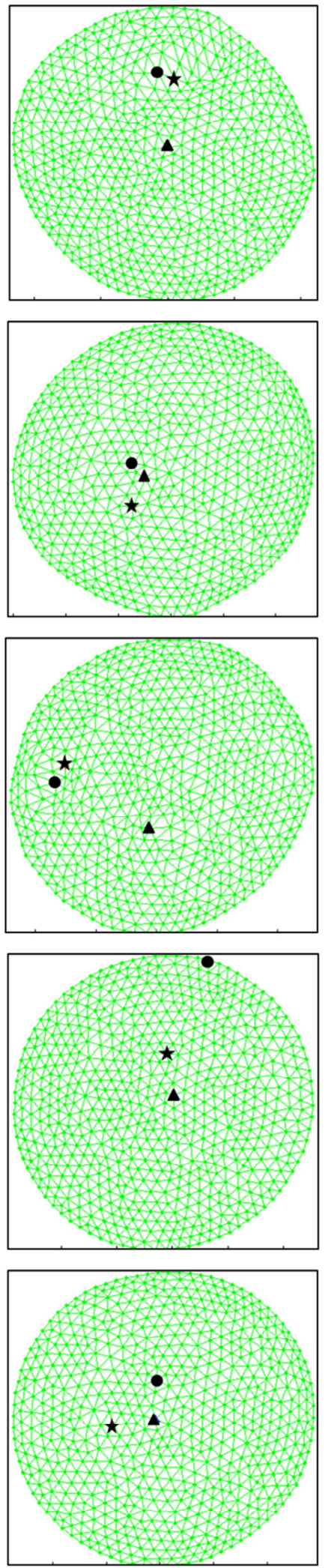

c) Rupture picture
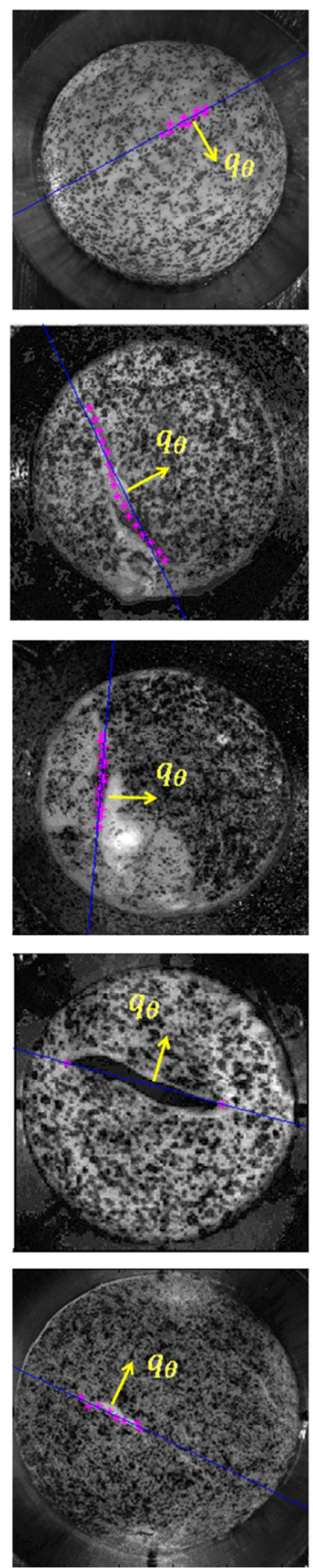

Fig. 8. ATAA rupture. For each test, a) the color map of the thickness measurement, b) the deformed mesh $(O=$ NodeMAX, $\Delta=$ NodeTOP, $t=$ NodeRUP $)$ and $c)$ the rupture picture where $q_{\theta}$ is the unit vector perpendicular to the rupture. 


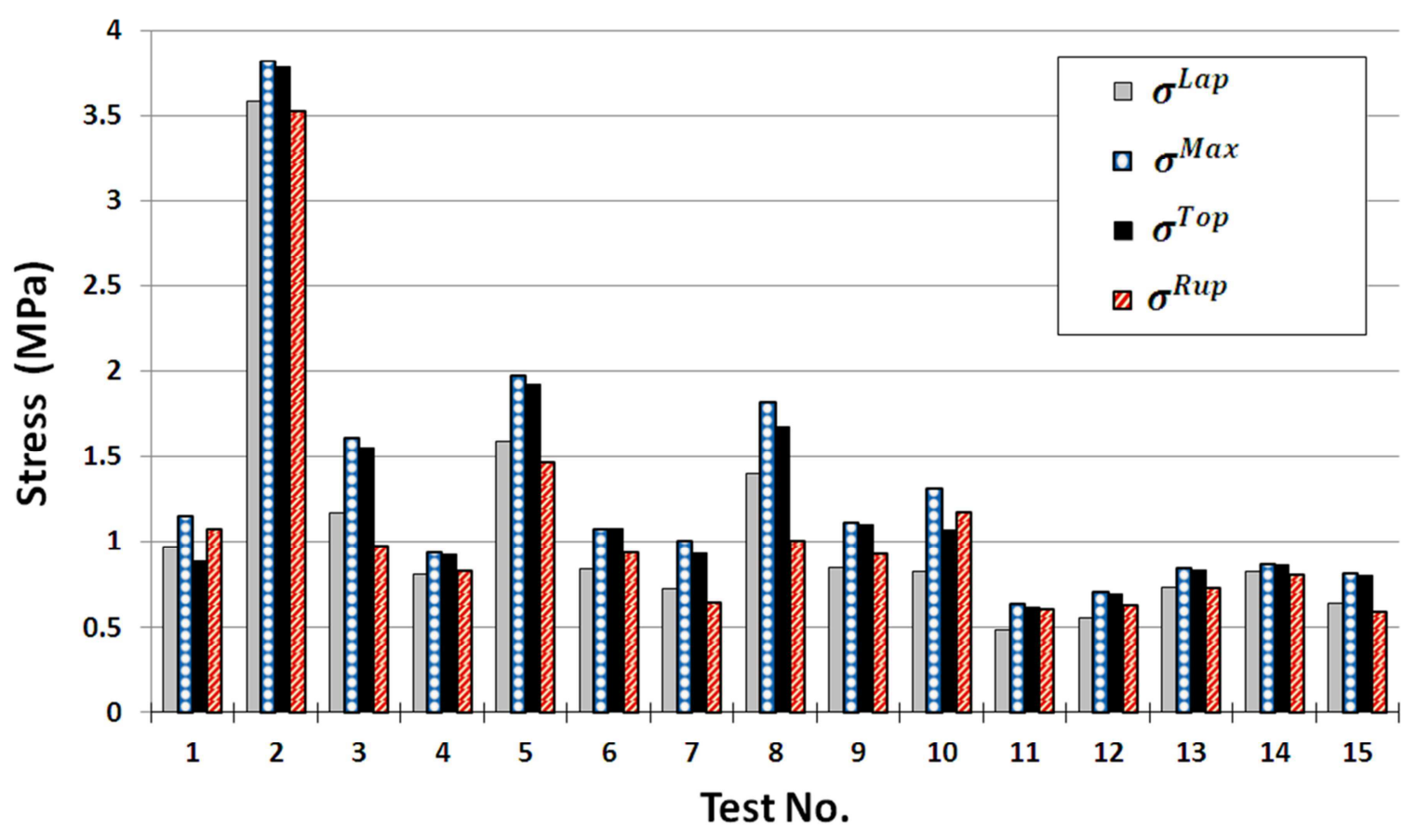

Fig. 9. Four different ultimate stresses for each of the 15 ATAA samples where $\sigma^{\text {Lap }}$ is the Laplace stress calculated from Eq. (12), $\sigma^{\operatorname{Max}}$ is the maximum principal stress, $\sigma^{T o p}$ is the maximum principal stress at the node of the top, and $\sigma^{R u p}$ is the rupture stress calculated from Eq. (10). 


\section{Thickness evolution $(\mathrm{mm})$}

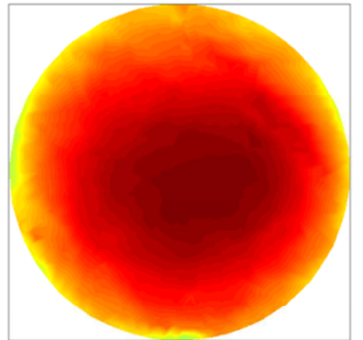

$0.003 \mathrm{MPa}$

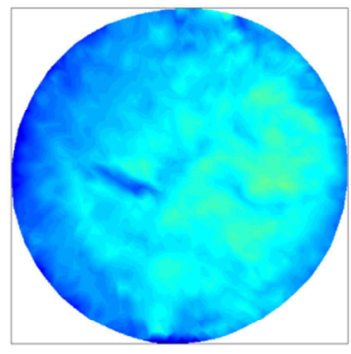

$0.048 \mathrm{MPa}$

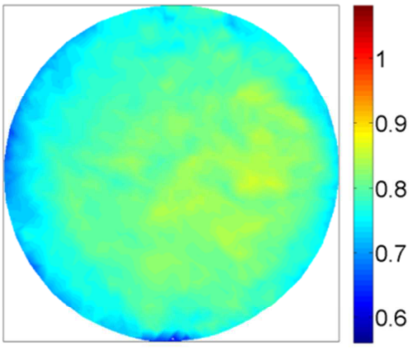

$0.018 \mathrm{MPa}$

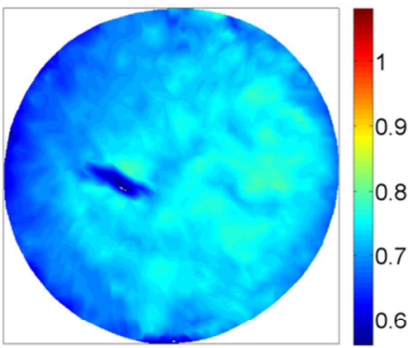

$0.057 \mathrm{MPa}$

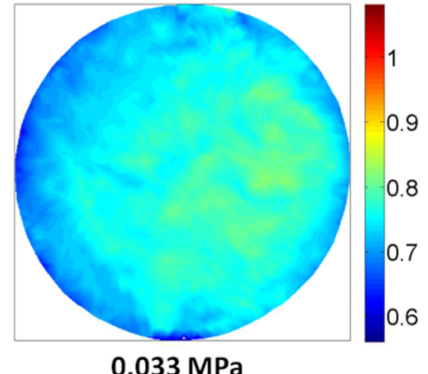

$0.033 \mathrm{MPa}$

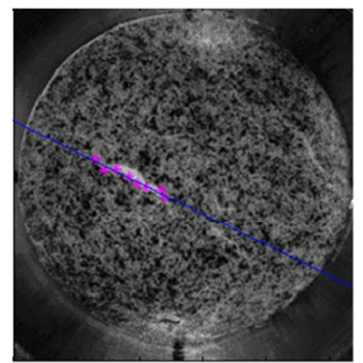

Rupture

Fig. 10. Local thickness evolution (Eq. (11)) in $\mathrm{mm}$. for one representative ATAA sample (Test No. 14). Top view from the initial stage $(0.003 \mathrm{MPa})$ until the final stage $(0.057 \mathrm{MPa})$ and the image captured by the DIS-C system at rupture are presented. 


\section{APPENDIX A}

2 To validate the membrane assumption the stress fields calculated by our approach on a pre-defined

3 geometry were compared to reference stresses provided by a finite element analysis (FEA) on the

\section{Validation Process}

A FEA simulation of the inflation process was performed with the aim to numerically reproduce an experimental dataset. Using the Abaqus $^{\circledR}$ software we created a $0.85 \mathrm{~mm}$ thick circular patch of 30 $\mathrm{mm}$ of diameter, corresponding to the area of interest (AOI) for an inflated of the experimental aortic layers. In order to perform the numerical simulation it was necessary to define the material properties of the circular patch, which were based on the anisotropic hyperelastic Holzapfel-GasserOgden (HGO) model (Holzapfel et al. 2000). The material properties defined for the FEA simulation were obtained from the literature: density= 5.0e- $4, C_{10}=0.0764 \mathrm{MPa}, D=1 . \mathrm{e}-8, k_{1}=0.0839611 \mathrm{MPa}$, $k_{2}=1.2644611, k=0$ and $B=41^{\circ}$.

The nodes on the boundary of the circular patch were pinned allowing their rotation. The applied load was defined as a uniform pressure of $0.06 \mathrm{MPa}$, applied to the inner surface of the circular patch (Fig. A1). Finally the mesh size of the simulation was defined by 10119 nodes and 19887 shell elements. 


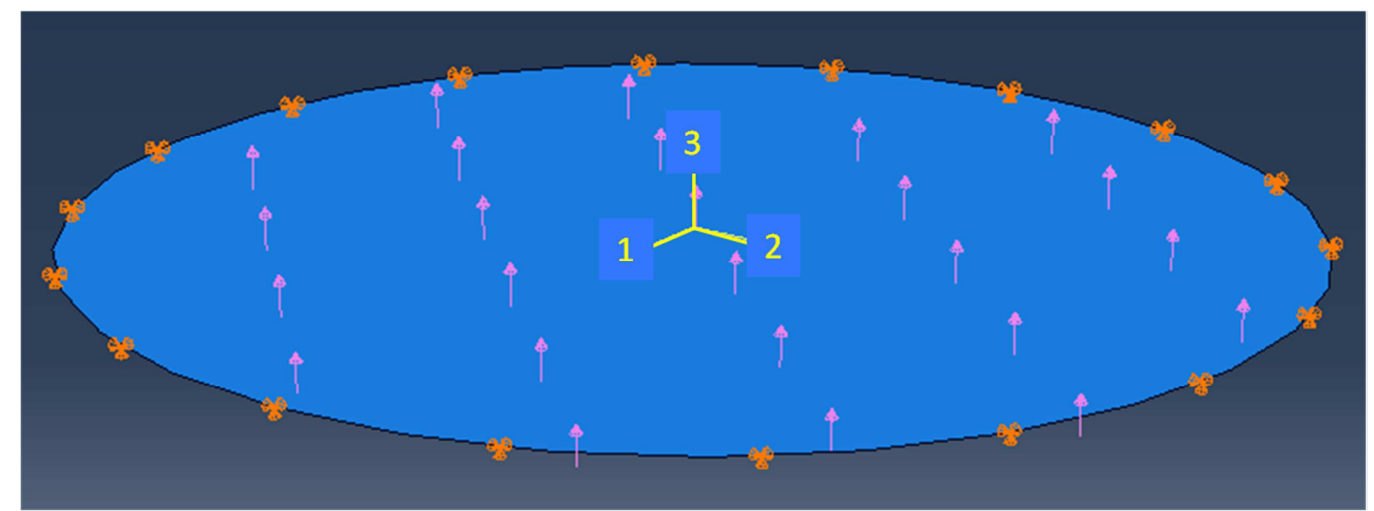

Fig. A1. Lateral view of the circular patch created in Abaqus ${ }^{\circledR}$ software. Boundary conditions allow the rotation. A uniform pressure is applied to the inner surface of the patch.

The FEA simulation provided the displacement and stress distributions at the end of the inflation. The stress fields provided by this FEA simulation were then used as a reference for the validation of our approach and the final geometry provided by this FEA was also used as the reference geometry for validating our approach.

For our simulation, we used shell elements which yielded two sets of stress fields in the results, one located at the inner surface (Fig. A2-a) and another located at the outer surface (Fig. A2-b) of the inflated membrane. The stress at the inner surface was slightly lower than the stress at mid-thickness and the stress at the outer surface was slightly higher than the stress at mid-thickness. For a $0.85 \mathrm{~mm}$ thick sheet, it was estimated that the mean absolute difference between the stress at the inner and outer surface was $0.32 \mathrm{MPa}$ for $\sigma_{11}, 0.26 \mathrm{MPa}$ for $\sigma_{22}$ and $0.0013 \mathrm{MPa}$ for $\sigma_{12}$. In contrast, our approach provides directly the stress field at mid-thickness. Knowing this, the two stress fields, outer and inner, obtained from the FEA simulation were averaged to provide an accurate comparison with our approach. 
a)
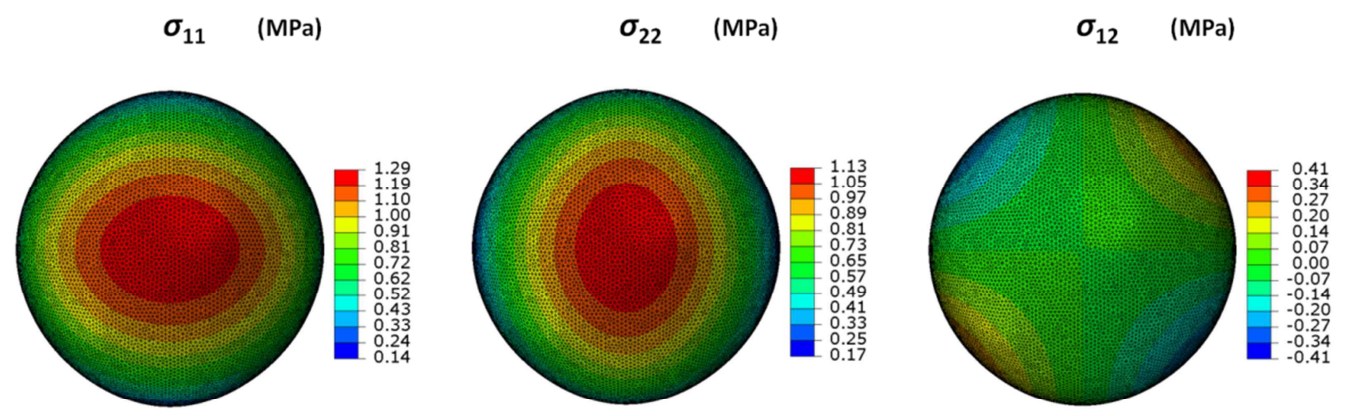

b)
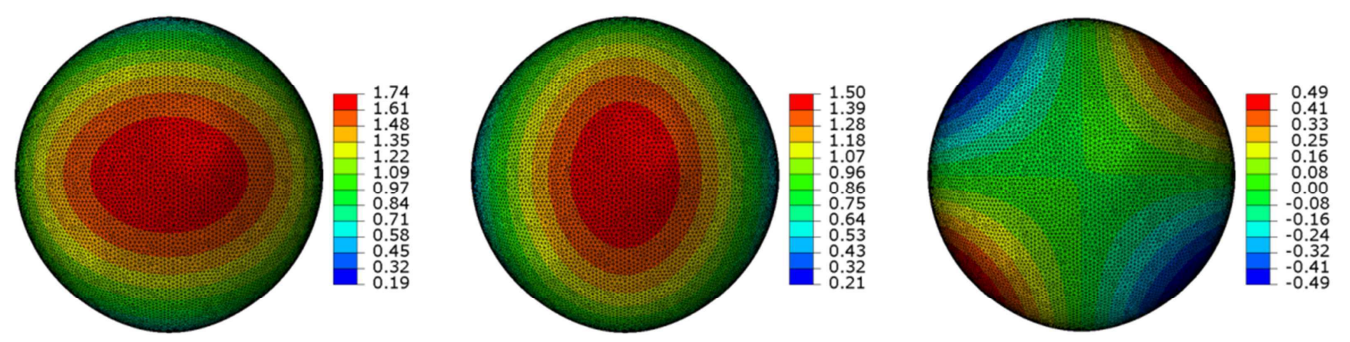

Fig. A2. FEA computation (Abaqus ${ }^{\circledR}$ software top view) provided stress fields located at a) the inner surface and b) the outer surface of the inflated membrane.

After extracting the nodal displacements, we interpolated the values across a grid of pixels in order to create a dataset with the same spatial resolution as the experimental data (Fig. A3). Then we applied our approach to these experimental-like data in order to reconstruct the maps of the Cauchy stress tensor. Using the Abaqus $^{\circledast}$ output file, we interpolated the stress values at the same nodes that we reconstructed them. Afterwards our Cauchy stress estimates, from applying our approach to the experiment-like data, were compared to the Cauchy stress values provided by the FEA computation. 


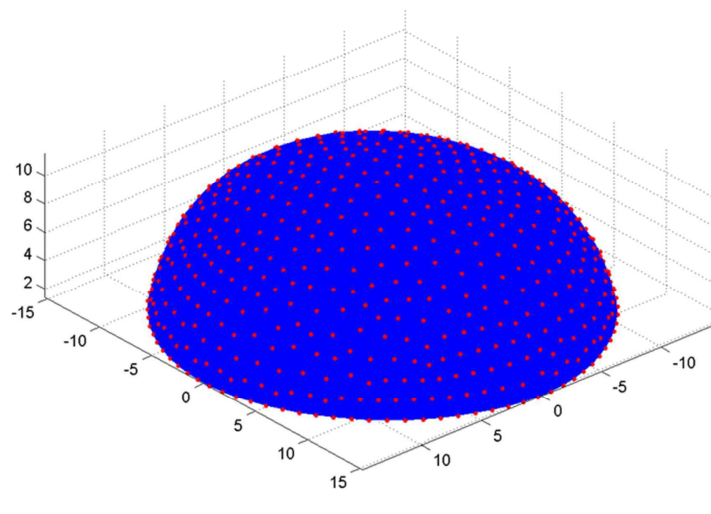

a)

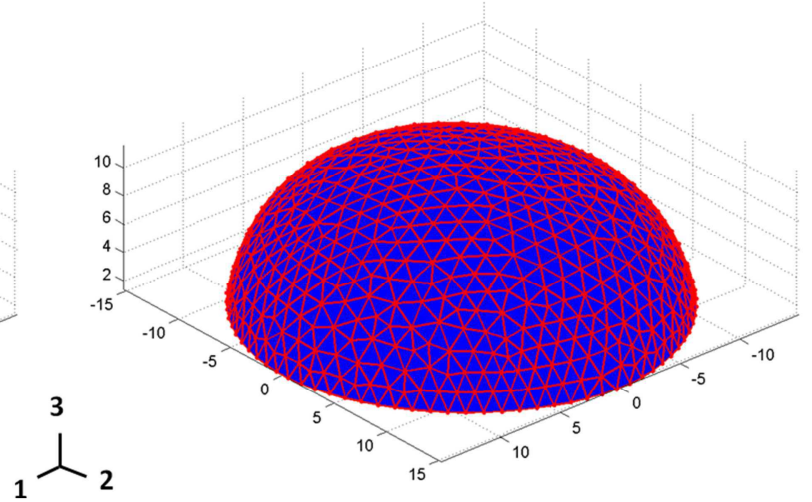

b)

Fig. A3. The 3D deformed geometry (surface) obtained with the FEA simulation (blue) was imported into Matlab $^{\circledR}$

a) Nodes where the Cauchy stress will be estimated are defined (red dots) across this surface

b) The surface is meshed using the Delaunay triangulation.

50

Therefore, we were able to compare, element by element, the results of our approach and those of a reference FEA simulation. In Figure A4-a the reference stress distribution from the FEA simulation is shown and in Figure A4-b the stress distribution from our approach is displayed. The difference between both was calculated at each element and is presented in Figure A4-c. Mean absolute errors of $0.031 \mathrm{MPa}$ for $\sigma_{11}, 0.002 \mathrm{MPa}$ for $\sigma_{22}$, and $0.005 \mathrm{MPa}$ for $\sigma_{12}$.were calculated between our approach and the FEA simulation. These mean absolute errors are equivalent to mean relative errors of $3.5 \%$ for $\sigma_{11}, 0.3 \%$ for $\sigma_{22}$ and $0.5 \%$ for $\sigma_{12}$. 
a)
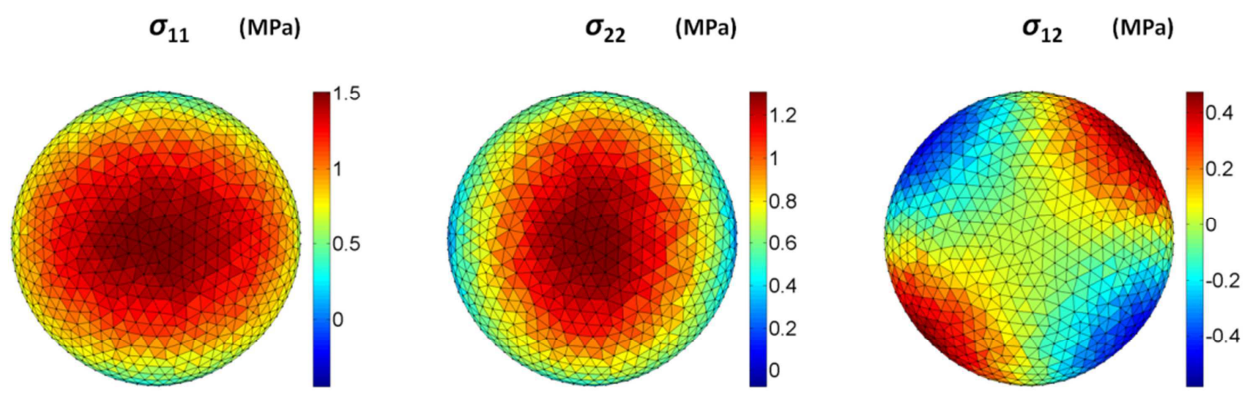

b)
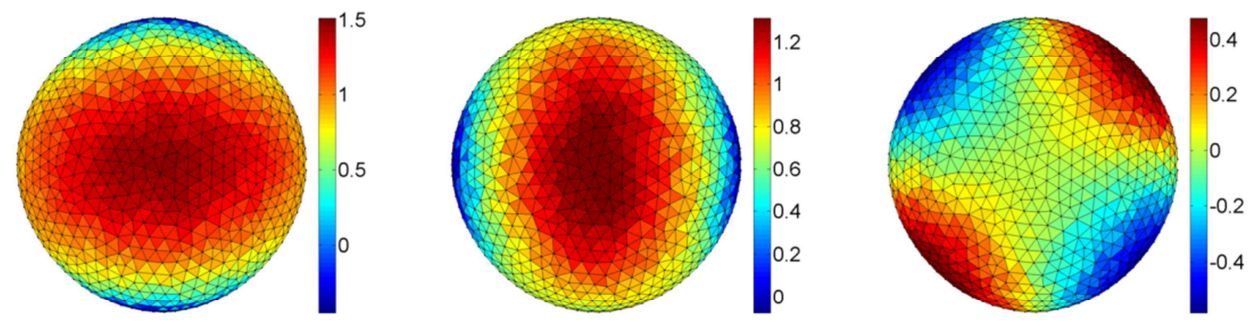

c)
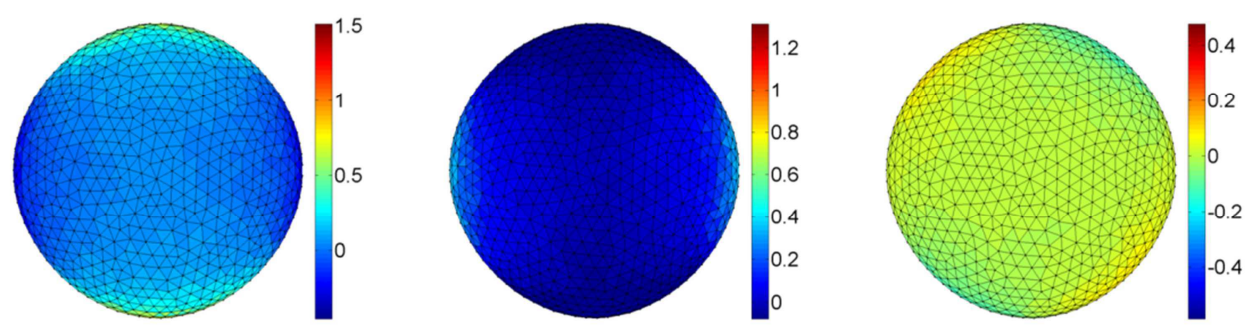

d)
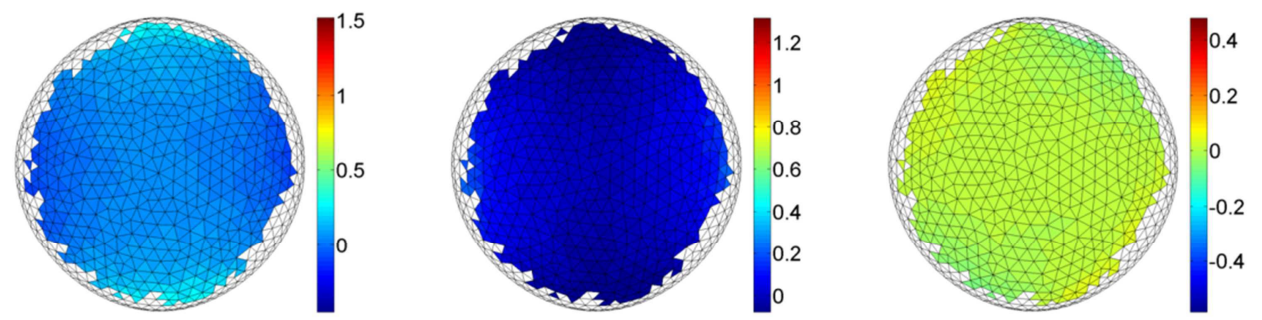

Fig. A4. Top view of the element by element comparison between stress fields calculated by a) the FEA simulation (reference) and b) our approach. The absolute error (in MPa) between a) and b) is presented in c) and in d) where the boundary elements are neglected.

The differences in the results are due to the different boundary conditions used for each method (i.e. pinned for the FEA approach and traction boundary conditions for our approach). An interesting result was that the boundary conditions only affected the estimated stress near the border. After removing the three first stripes of triangles adjacent to the border (Fig. A4-d), the mean absolute errors were reduced to $0.008 \mathrm{MPa}$ for $\sigma_{11}, 0.013 \mathrm{MPa}$ for $\sigma_{22}$, and $0.008 \mathrm{MPa}$ for $\sigma_{12}$. These mean absolute errors are equivalent mean relative values of $0.8 \%$ for $\sigma_{11}, 1.4 \%$ for $\sigma_{22}$ and $0.8 \%$ for $\sigma_{12}$, indicating that the stress estimates contain some errors along the border due to the assumed 
67 boundary conditions but these errors vanish rapidly away from the border. 